\title{
Evaluation of an E-participation Project: Lessons Learned and Success Factors from a Cross-Cultural Perspective
}

\author{
Peter Parycek, Michael Sachs, Florian Sedy, and Judith Schossböck \\ Danube University Krems, Dr. Karl Dorrek-Straße 30, A-3500 Krems, Austria \\ \{peter.parycek, michael.sachs, florian.sedy, \\ judith.schossboeck\} @donau-uni.ac.at
}

\begin{abstract}
In the area of large-scale e-participation projects on a cross-national level, the project we present is based on the idea that the active involvement of young people in the process of socio-political decision-making plays an important societal role. OurSpace is a multi-national project supporting a closer relationship between European decision makers, and Europe's younger generation. OurSpace tried to combine ICT usage, young peoples' readiness and motivation to participate, and their assumed lack of information regarding European politics. We present the evaluation framework and methodology applied for OurSpace, the major results of the project evaluation, and the lessons learned from a comparative perspective.
\end{abstract}

Keywords: e-participation, online deliberation, evaluation, youth, Europe.

\section{Introduction}

Citizenship builds upon our right to participation, and ideally participation should be equal, inclusive and made as easy as possible. Due to the increased usage of the internet and the democratic deficit felt, e-participation projects are often based on the idea to facilitate participation and to attract the attention of a specific target group, in particular those attracted to the usage of ICT. E-participation experts have emphasised that further investigation should be done in two areas: first, the ,applicability of e-participation tools to particular contexts“, and second ,assessing the social acceptance of e-participation", i.e. the evaluation of such projects and tools [1]. Conceptualising the methodological frameworks of e-participation evaluation has thus become a relevant topic in the field [2]. OurSpace is a multi-national project specifically aimed towards bringing European politics and decision makers closer to the European youth. Young people are principally motivated to participate [9] in participating in political online forms and they often prefer online to offline forms [10]. They are frequently seen to possess the necessary capabilities for e-participation projects due to having grown up with digital media. The term „Digital Natives“[2] (often falsely) implies that those who grew up with the internet also navigate more 
easily in online environments. Obviously, to use ICTs for participation also requires cognitive capabilities that enable the individual to decide between alternative opportunities and to recognise them in an online environment.

The methodology covered technical suitability and usability as well as young people's opinion on a specific deliberation tool. The following aspects were relevant:

- How do young people navigate in a multi-level e-participation environment?

- How relevant do they find the discussions and how much do they trust the outcome of this specific tool?

- Can e-participation projects for the young lead to more interest in politics or politicians from the target group?

- What can be said about the nature of discussions between the young and politicians online and how they interact?

- What chances and difficulties can be observed from a cross-national perspective, i.e. in cross-country online deliberation?

The EU project provided an online deliberation space designed to actively engage young European citizens, in particular young citizens from Austria, the Czech Republic, Greece and the United Kingdom. ${ }^{1}$ These countries with different socioeconomic situations ran pilots that promoted the project on both the national and European level. The project provides an online deliberation space designed to actively engage young European citizens.

\section{Evaluation Methodology}

Building on already existing research on e-participation evaluation, the OurSpace evaluation model offers a methodology with reference to the methodological framework developed by Macintosh [1] and extended by the consortium. In the following, the authors will describe the methodology, the tools and the circumstances of the evaluation. The evaluation of the open stage focused on a mix of qualitative and quantitative data. This data is related to the complete project, and interviews were done in the later project stages (since October 2013). ${ }^{2}$ The external test stage, in autumn 2012, focused on 200 user tests, which covered important aspects of usability and functionality of the platform. The open stage started at the beginning of September 2012, when the platform was opened to users and promotional activities with the ambitious goal of engaging 6.000 users. By the end of March 2014, around 4.870 users have been registering on the platform.

The state of e-participation has been studied by the Demo-Net Network of Excellence: The country reports in Coleman et al. [4] emphasise context information

\footnotetext{
${ }^{1}$ See aims and scope oft he project under the official EU project site

http://www.ep-ourspace.eu/Project/Approach.aspx (accessed March 27th, 2014).

${ }^{2}$ For downloads of the Deliberables and Publications, see http: //ep-ourspace.eu/Downloads/Deliverables.aspx (accessed March 27th, 2014).
} 
on institutional and political conditions. Several e-participation researchers highlight the importance of systematic analysis of processes and outcomes against predefined criteria [5]. They make the assumption that "benefits to be gained from evaluation are manifold" [5] e.g., identifying conditions and extent of success as well as deficits. In the context of OurSpace, evaluation models provide a structured analysis model for estimating how far an e-participation project can help to enhance certain aspects of democracy like citizens interest in politics. The evaluation of e-participation is still in its infancy and there is a need to develop a coherent framework, encompassing a range of perspectives and research methods [6]. The OurSpace project seeks to adopt the assumption that contexts frame some participation processes and will take a closer look at the political and social perspective of evaluation, which is reflected in the relevant indicator categories of the evaluation methodology.

\subsection{Tools}

Online Questionnaires: For the final evaluation, two different questionnaires were conducted: A short questionnaire for direct integration into the website, which users reached via a feedback button directly on the website and a long questionnaire with detailed questions. 310 feedback questionnaires were filled in and 76 were counted, whereas for the long questionnaire, the evaluation builds on 420 responses.

Interviews (3 experts, 12 users, 6 decision makers): Three types of interviews were conducted: Users, experts and decision makers in all pilot countries. Whereas the guidelines were constructed for face-to-face interviews, only user and expert interviews were done in person. Most of the decision maker interviews were done in written form due to time constraints of this target group. The interviews were conducted in November and December 2013. Interview guidelines followed the relevant indicator levels of the evaluation methodology. The user category refers to citizens that have chosen to register for OurSpace services and have been active on the site. Decision makers interviewed included representatives from political parties, officials from the EU, and national or regional agencies. The interviews with experts were done with national and international e-participation experts.

Discourse Analysis: Aspects of online deliberation from a qualitative perspective were analysed according to pre-defined criteria: Pilots analysed exemplary discussions on the platform according to criteria for successful online deliberation. For this analysis, all pilots chose two topics relevant for discourse analysis, most of them being successful discussions with significant numbers of user comments.

Evaluation Workshop (12/2013): Additionally to the tools described above, the consortium conducted a focus group dedicated to the evaluation. This workshop took one and a half days and was organised by DUK, and took place in London on December 5-6, when most data had been collected and pre-assessed. In the focus group the main outcomes, conclusions, and recommendations of the OurSpace project were discussed. 
Platform Data and Google Analytics: By using the available platform data in combination with Google Analytics it was possible to evaluate activities during the project period. Furthermore, data from social media platforms like Facebook and statistics related to the OurSpace blogs were analysed.

\subsection{Overview of the OurSpace Methodology}

Studies focusing on e-participation effects and evaluation have increased over the last few years [7]. In this context, several conceptual and methodological frameworks have been proposed. Kubicek et al. [8] introduce a structural model for analysing and evaluating participation initiatives on a general level. The Demo-Net consortium elaborating on Macintosh and Whyte [1] - suggests a three-layered model stressing different levels of e-participation objectives, an approach that integrates the following perspectives: Project perspective, socio-technical perspective and democratic perspective. The OurSpace methodology adapted this approach suggested in Macintosh and Whyte [1]. Kubicek et al. [8] also analysed participation projects with relation to their success and defined success factors in relation to the existence of "strong links to formal political decision making" [8]. This perspective was covered with various questions in the OurSpace evaluation: Both users' opinion on the outcomes of the projects as well as decision makers opinion regarding the actual impact of the discussions were analysed. The category of the political as context factor has been added to the OurSpace evaluation framework, whilst putting less emphasis on the project perspective.

OurSpace as a multilingual project with a multi-national, European focus has to take into account several political, but also socio-cultural frameworks. In this paper, results of the different evaluation perspectives will be summarised and should be interpreted and read along the different political situations. The methodological overview is influenced by the framework of Aichholzer and Westholm [5], who link different aspects along the three layer evaluation model to the relevant methodology. The OurSpace evaluation builds on two main perspectives of the project; a technological and a socio-political perspective. The categories as proposed by Macintosh have been further divided into four evaluation level categories.

1. A political evaluation level: Although the democracy perspective and political aspects are the most difficult ones to analyse, OurSpace, according to one of the main goals of the project, respectively evoking young people's interest for politics and democracy, focused on aspects of influence on political decision-making and relevance of the discussed topic for politicians and decision makers involved in this level.

2. A technical evaluation level: On this level, platform and tools usability and suitability were assessed.

3. A social evaluation level: The social perspective covers aspects of society related to community-orientation and connection more than aspects of politics and decision making. On the social level, community-building and (digital) connections between users will be measured. Special emphasis is also given on the integration of multiple communication channels (web, mobile and social media channels). 
4. A methodological evaluation level: This level comprises methodological questions related to the effectiveness of the essential success factors and characteristics of the platform: The deliberation model, dissemination activities and the effectiveness of user engagement tactics.

Translating these perspectives into indicator categories, the OurSpace evaluation framework comprises the following categories:

- Political level: 1. Relevancy and Popularity of selected deliberation themes, 2. Effectiveness of communicating the trial results to decision makers and relevant public bodies, 3. Degree of influence on decision-making processes and political actions

- Technical level: 1. Platforms and tools usability, 2. Platform purpose suitability

- Social level: 1. Effectiveness of integrating multiple evaluation tools, 2. Digital connections created between users, 3. Quality of discussion and deliberation process

- Methodological level: 1. Effectiveness of deliberation model, 2. Effectiveness of dissemination activities, 3. Effectiveness of user engagement tactics.

\section{$3 \quad$ Results}

The following refers to the most visible results with reference to all pilot countries. In accordance with other findings of user activity in e-participation, there was only a small amount of users actively posting on the website in relation to those just "lurking" and not getting active. Most other users used participation options with a lower participation threshold, such as likes and thumbing, which is sometimes also known as gamification elements in e-participation [11]. Since launch of the platform, the site has counted 52.000+ visitors, 29.000+ unique visitors, 338.000+ page visits and $18+$ active decision-makers. The average user looked at $6+$ pages and stays for $6+$ minutes. On the technical level, users were satisfied with the technical features and functionality of the platform. Around $60 \%$ liked the look and feel of the platform, and $74 \%$ in total found it easy to navigate. Despite those good results, observations of workshop leaders also revealed that there were sometimes difficulties with navigation, and additional guidance, in particular regarding the stages of the evaluation process and regarding the possibility to post proposals, were needed. Suggestions for improvement on the basis of interviews and the questionnaires included wishes for a more modern design, the enhancing of visibility and more interconnectivity. Users wanted to create groups between members and add more information about users.

\subsection{Political Level: Interest in Politics and Trust}

Regarding the relevance and popularity of the selected topics, experts, users and decision makers were generally very positive about the topics ( $74 \%$ of youth stated they found the topics relevant or very relevant). Users were able to create their own topics on the platform (which might have influenced this result to the positive). 
Table 1. Relevance of deliberation themes for youth

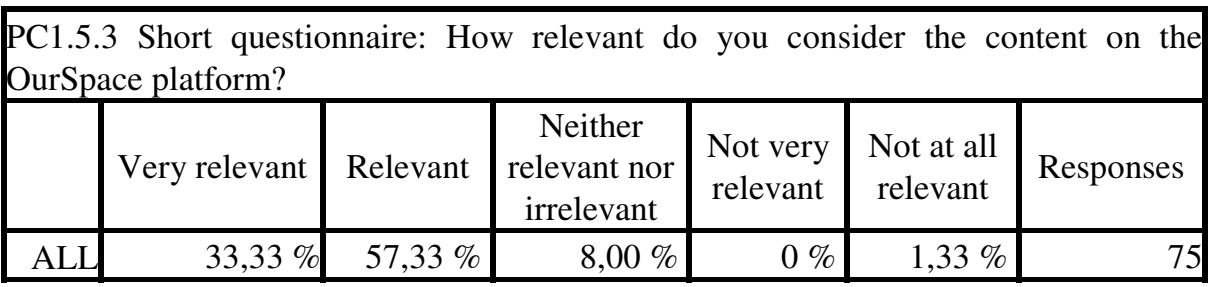

One of the major challenges of the project was to get young people in contact with decision makers who participated not equally throughout the countries, and continuous contact with decision makers was needed. Those who participated engaged actively with youth and most of the time also addressed them directly. The discourse analysis showed that in most cases decision makers only gave feedback one time and youth did not respond a second time to that feedback. Despite a few successful showcases of engaging decision makers, users still asked for more decision maker involvement, and in some countries they were almost completely absent. In Austria and due to direct contact with politicians decision makers responded to almost every thread they opened, and $40 \%$ of MEPs participated on the platform by opening their own topic. In Greece, no decision maker participated actively in discussions. In the UK, two MEPs answered in the results phase, but not during the discussions.

Users and decision makers agreed on the potential of the platform but were indifferent about the impact on political work. Those politicians who participated in the platform were very positive about the impact on their political work, albeit this can be seen as mostly inspirational impact. In the Czech Republic, actual policies were discussed and users were therefore slightly more positive about the platform impact on such policies. Users were indifferent regarding whether the platform made them more interested in the work of a politician. Results of the questionnaire showed that they were positive regarding the potential of an e-participation tool to bridge the gap between decision makers and youth, and $75 \%$ stated in the questionnaire that they think platforms like OurSpace are good to get involved or more interested in politics.

Table 2. Potential of e-participation platform for getting more interested in politics

\begin{tabular}{l}
\hline $\begin{array}{l}\text { Long questionnaire: Taking into consideration the above, do you think that } \\
\text { platforms like OurSpace are good to get involved or more interested in politics? }\end{array}$ \\
\hline \\
\hline
\end{tabular}

Users were indifferent (and slightly more positive in $\mathrm{CZ}$ ) regarding the question whether they would be more interested in the work of a politician in the interviews. 
Table 3. E-participation platform and getting more interested in the life of a politician

Questionnaire: Did you get more interested in the work of a politician that you met/that posted on OurSpace?

\begin{tabular}{|l|r|r|r|r|r|r|}
\hline & \multicolumn{1}{|c|}{ Yes } & Rather yes & Neutral & Rather no & No & Responses \\
\hline AT & $17,96 \%$ & $25,15 \%$ & $29,94 \%$ & $10,18 \%$ & $16,77 \%$ & 167 \\
\hline CZ & $16,28 \%$ & $27,91 \%$ & $16,28 \%$ & $18,60 \%$ & $20,93 \%$ & 43 \\
\hline GR & $6 \%$ & $14 \%$ & $42 \%$ & $15 \%$ & $22 \%$ & 85 \\
\hline UK & $21 \%$ & $19 \%$ & $37 \%$ & $6 \%$ & $16 \%$ & 62 \\
\hline ALL & $15,41 \%$ & $21,85 \%$ & $32,49 \%$ & $11,76 \%$ & $18,49 \%$ & 357 \\
\hline
\end{tabular}

Only $33 \%$ stated the platform could improve their trust in politics, although they said the platform would have the potential to better informing users about political issues and making people more interested in politics. While most users did not find that the platform could improve trust in politics and politicians, a lot of them were also indifferent regarding that question (35\%). Czech users were far more positive in this regard: $81 \%$ of Czech users found that the platform has helped them to improve their trust in politics and politicians, compared to $43 \%$ of Austrian users. The worst result regarding trust and politics was seen in Greece: Only $18 \%$ of Greek users stated it could help them to improve their trust in that matter. The importance of trust in politics has long been emphasised by political theorists, and there is evidence that this is still the case, in particular on national level [12]. The different numbers regarding trust in politics correspond with other comparative or national findings regarding trust. For instance, Austria is behind many CEE countries regarding trust in politics, and numbers have been going down considerable during recent years [13]. However, around $50 \%$ of Austrians trust the Austrian government according to a 2014 survey by Gallup [14], and results of the OurSpace survey among young showed a similar picture like surveys among the general population in most pilot countries. Statistics also have shown that trust in politicians is higher on the local level [15], and e-participation projects have been related to the hope of bringing politicians closer to people by bringing them into direct contact with participants. The majority of young users felt empowered or very empowered (59\%) by the platform, based on the results of the short questionnaire that was put online. A bias has to be taken into account here as these responses were small in number and most likely coming from people who were very interested in the platform anyways, probably displaying a generally very positive view on e-participation. Summarizing, results show that the young are ready to engage and credit e-participation platforms much potential, but it is hard to engage people beyond the easy user group of already politically interested people.

\subsection{Social Level: Inclusivity, Connections and Discussions}

Emploeying social media channels was important for getting people engaged in the project and an essential part of the dissemination strategy. Mobile access, however, proved to be less important than expected: the majority of users accessed the site 
through regular means, i.e. the website version of the platform. It has to be pointed out that this is also due to engagement tactics and promotion strategies which clearly focused on the website version, whereas mobile versions like the Android application were only advertised throughout the beginning of the project and less so from the open stage, as they were not taken on by users. This shows that mobile applications will not be used automatically but have to be continuously promoted. Compared to the general access via the OurSpace platform (mobile and non-mobile), it has to be concluded that alternative forms of access like applications were less interesting for the typical OurSpace user than initially expected. This also correlates with data from Google Analytics: about $12 \%$ used mobile devices to access the platform (however they did not use the Android app for this). Regarding registration, social media (Facebook Connect) was an important feature and $36 \%$ of users registered via this option on the platform. Nonetheless, registration via email or Facebook Connect also opens up a barrier to participation, and it should be discussed whether registration is necessary at all stages of the deliberation process in e-participation in order to increase inclusivity. Links between users and decision makers have been made, yet participating decision makers faced time limits, which could be seen as a major obstacle to the sustainability of connections made and to getting feedback to the threads on the platform. However some countries were very successful regarding collecting decision maker feedback, e.g. Austria where every decision maker posted feedback to the thread they opened, although this had to be supported by continuous reminders and by contacting the offices of the politicians. The discourse analysis showed that discussions displayed a variety of users, gender and countries and in 6 cases, cross-national debates with users from three different countries were found. The tone of the discussion was generally friendly and content-related moderation almost not necessary. However, language could still be seen as major hurdle regarding cross-country deliberation, with most of the cross-national debates happening on the EU layer and in English. If moderation was required, it was mostly in relation to process, e.g. proposals that had been supported by moderators or comments turned into proposals, as only from 4 proposals a thread could reach the last phase of the deliberation process. Very often, despite users being very satisfied with the 4 stages of the model in the questionnaire and interviews (69\% were very satisfied or satisfied with the platform for political debate as a whole in the questionnaire), it seemed that they did not understand or realise those option, so it was often overseen by users. This had to be amended by moderators pointing out that option and sometimes turning comments including a solution into a proposal.

\section{$4 \quad$ Lessons Learnt and Best Practices}

The following section summarises the lessons learnt throughout the project related to quality of discussions as well as some parameters of analysis like transparency and the multi-level conception of the e-participation tool. 


\subsection{Best Practices Discussions (Deliberation Process)}

The platform displayed different levels of activity in different pilot countries: Regarding the thumbs per pilot, it is visible that this activity is used in Austria more often than in the UK, related to the number of registered users. Users in the Czech Republic use this feature the most and more often than postings - this makes the Czech user a very active user compared to the average user in other countries. This underlines again that the Czech discussions are most vibrant and engaging, despite their position in the general user ranking. Of course, thumbs are no indicators of a good quality discussion but they indicate interest of the users in the discussion.

There has been active participation of decision makers (CZ, AT, UK) and the Austrian pilot can be seen as a best practices example of how to integrate decision makers in the discussion process. Crucial in this case was that moderation and community management was necessary, as well as constant reminders of decision makers or their offices to receive feedback or postings on the platform. This lead to the result that one third of all Austrian MEPs were active on the platform.

Controversial topics proved to be most successful and the topics mentioned in the pilots at a glance section give an overview about which topics have been most successful. Apart from that, topics that concerned the rights of a minority (e.g. rights of homosexuals), education (e.g. votes at 16) and environment (e.g. climate change) could be identified as topics with high potential for discussion. Moderation of topics was still necessary, both online (in particular reminders of MEPs and regarding the treatment of proposals (process-orientated moderation) and offline (e.g. guidance at workshops with youth regarding the platform or deliberation process).

\subsection{Inclusiveness and Transparency}

Regarding transparent and inclusive participation, OurSpace moderators followed a procedure to inform users about the reasons for deleting postings and so moderators were transparent in their moderation activities. All parties of the political spectrum and a broad variety of gender and age were invited, and user diversity showed that this was successful.

Regarding cross-country deliberation, the OurSpace platform offered the opportunity to engage in such discussions by using the Google Translate tool and keeping debates open for all users from every pilot country. However, language can still be seen as the major obstacle in cross-country deliberation.

Another barrier was people being increasingly critical about the registration process and giving away their e-mail (this is related to privacy concerns, but also related to avoiding spam or information overflow). This suggests that future models of registration should keep that barrier low. It is debatable whether all stages of the deliberation process or all e-participation stages in general ask for registration. Some users can be very critical about the registration process and both Facebook Connect and email registration offer major hurdles that have been confirmed by users in workshops and other feedback. However, as the platform was based on counting user numbers as well as further engagement increase by user recommendations, it was necessary to distinguish between registered and non-registered users in the OurSpace case. 


\subsection{Acceptance of the Four Stages Deliberation Model}

There was general a good evaluation of the four stages evaluation model. Eparticipation expert Kühnberger mentioned in the interview that e-participation usually follows a layer approach, and different levels in e-participation are a common procedure. Users stated that the model helped them to be more politically informed and thus trusted that the platform enabled them to place better political decisions, as well as generally being more empowered in the area of politics. They credited the platform a lot of potential and were satisfied with the suitability of the platform for its purpose. However, even though users liked the deliberation model per se, the details of the four stages of the deliberation model, in particular the options to hand in proposals, wasn't understood or taken on by many users. Users also pointed out that they liked the cross-country approach of the deliberation model.

Summarising, users were satisfied with the technical features of the platform, in particular regarding the purpose of the platform. If there were suggestions for improvement, they were mostly related to interconnectivity and visibility, or requests for a guidance through the process, which the project reacted and responded accordingly by making certain threads more visible and by integrating an explanatory tool (page guideline) related to the four stages of the decision making process on the platform. It has to be noted that without moderation from the consortium and the community managers, the four stages of the model according to the previously defined rules (e.g. a significant number of proposals were necessary before a topic could reach the last phase) could not have been realised.

\subsection{Barriers in Cross-Country Deliberation}

The challenges in cross-country e-participation projects are still related to the feedback of decision makers, and despite good results in some countries (e.g. Austria) other countries like Greece decision makers almost didn't participate at all. The impact on policy making as perceived by users did not exceed the inspirational. Users were critical whether such projects would improve the general trust in politics and whether the socio-political conditions in the pilot countries seemed to be dominating the outcome of the project. Users did not trust the political impact of a debate, which can also be related to the general political climate in the European Union and in particular the pilot countries that played a role in the project. The different results on whether such projects could improve trust in politics confirm the importance of the different political and economic situation in the countries. Different forms of user activity in the pilot countries could also be related to this, e.g. less active users in the Greek pilot as compared to the Czech pilot, even though the Greek pilot brought a lot of users in terms of user registration.

As emphasised, understanding the different stages of the deliberation process proved to be difficult, and the possibility of handing in proposals needed moderation and support as did the last phase (voting phase) of the deliberation process. This shows that multi-layer processes in e-participation need a lot of explanation and 
moderation, even for young users, who are often seen to be equipped with the necessary capabilities to participate online more naturally.

Another challenge was related to the understanding of politically complex content: Concrete legislation is difficult to discuss for users for this requires profound knowledge and adequate time to place an argument properly. Additionally, it was difficult to engage a target group beyond politically already active users, and to get people participating in discussions outside their own country or language group.

Another barrier was the registration process, which might have left out particularly critical user groups who did not want to register via email or Facebook Connect. Apart from registration, regular and everyday life communication channels like Facebook are most likely to be used. It was hard to get people away from already existing platforms onto a new platform as nowadays most users can easily debate a topic of their choice on social media platforms, and often prefer to do so.

Gender and other demographic data did not seem to be a problem in online participation in the OurSpace case, and female decision makers seemed to take part more actively in the process and users were equally distributed across the gender category. Cultural conditions might have been an obstacle regarding users participating in discussions in cross-cultural ways, and language has proved a major obstacle in cross-cultural debates despite an integrated translation tool (Google Translate) and many attempts by the consortium to get users from different countries to participate in a discussion. This was most successful for the EU layer; still discussions were mostly in English. Regarding political and cultural conflicts, those were handled well on the platform, and even very different political opinions were handled with a respectful tone making moderation mostly necessary related to process and not tone of discussions.

\section{$5 \quad$ Summary and Conclusion}

Summarising, the OurSpace project can be seen as a model for a diverse and politically interested young target group. It was, however, difficult to engage young people beyond the group of politically interested young people. Young users thought that reaching politicians can be a true feature of the platform and they believed that the platform could serve as a link between opinions of the young and decision makers. The content of the platform was seen as highly valuable by all interviewed groups, however, young people wished for more connections between users of the platform. Young people are generally very positive regarding e-participation as a tool for political engagement and informed decision making, even though they are critical about the outcome and they, as a tendency, do not think it can considerably improve trust in politics on a general level. They are critically regarding the political impact on policies and need guidelines when participating in large scale and multi-level e-participation projects on the process level. They are, however, very capable to engage in face-to-face and anti-hierarchal discussions with both politicians and other users, and to engage in respectful and inclusive deliberation online. Engaging decision makers on the platform was one of the major success factors and users expressed their 
wish to see more politicians on the platform. Getting a commitment from official institutions or decision makers should thus be priority and decision makers should be engaged from as early on as possible in designing e-participation projects. In terms of barriers that prevented users from active discussion, several ones have been depicted, such as: language barriers, higher interest in national rather than European topics and difficulties to navigate on the platform. While users gave positive feedback about the design and functionality of the deliberation process, the ratio of proposals to posts was not satisfying, as users did not come up with their own proposals as often as expected. This might be due to two reasons: The participation threshold for formulating your own solution to a political problem is too high for the average user, or not all users understood the proposal-functionality of the platform. It is thus crucial to promote all stages of the deliberation process and to offer participation opportunities with a lower participation level or threshold, such as liking or thumbing, where users can express their opinion by just promoting comments or proposals with a single click. The same applies to the participation threshold at the registration process: Retrospectively, e-participation, especially in a political context, should not require registration at all levels of participation. As complex discussions can lead to exclusion of less educated and elaborated people the threshold for participation for people who are less familiar with those topics should be kept as low as possible. For any e-participation project with an EU focus this can mean to include as much information on the EU and related processes as possible, as the EU is still an unfamiliar entity in the context of everyday life topics of young people. Additional information can be summarised in blogs, social media channels, or dedicated workshops. Similarly, social features and connectivity is important for users. It is thus advised to create social features users know from other social networking sites and services and to create links to those services (e.g. connection to user profiles, groups, communication possibilities between users, chat functions, thumbing etc.).

\section{References}

1. Macintosh, A., Whyte, A.: Towards an evaluation framework for e-participation. Transforming Government: People, Process and Policy 2(1), 16-30 (2008)

2. Sachs, M., Schoßböck, J.: Evaluation of e-participation projects. In: Parycek, P., Edelmann, N. (eds.) CeDEM13. Proceedings of the International Conference for E-Democracy and Open Government, pp. S.465-S.469. Edition Donau-Universität Krems, Krems (2013)

3. Prensky, M.: Digital Natives, Digital Immigrants. On The Horizon. MCB University Press, vol. 9(5) (2001)

4. Coleman, S., Freschi, A.C., Mambrey, P. (eds.): Making e-participation Policy. A European Analysis. [Demo-Net 14.2 and 14.4] (2009),

http://www.ssoar.info/ssoar/GetDocument/?resid=6677 (accessed March 27, 2014)

5. Aichholzer, G., Westholm, H.: Evaluating e-participation Projects: Practical Examples and Outline of an Evaluation Framework. European Journal of ePractice (7) (2009), http: / /www.epractice.eu/files/ 7.3.pdf (accessed March 27, 2014) 
6. Lippa, B. (ed.): D13.3 Demo-Net booklet e-participation Evaluation and Impact (2008), http://www.ifib.de/publikationsdateien/DEMOnet_booklet_13.3_ e-participation_evaluation.pdf (accessed March 27, 2014)

7. Medaglia, R.: e-participation Research: A Longitudinal Overview. In: Tambouris, E., Macintosh, A., de Bruijn, H. (eds.) ePart 2011. LNCS, vol. 6847, pp. 99-108. Springer, Heidelberg (2011)

8. Kubicek, H., Lippa, B., Koop, A.: Erfolgreich beteiligt? Nutzen und Erfolgsfaktoren internetgestützter Bürgerbeteiligung - eine empirische Analyse von 12 Fallbeispielen. Bertelsmann, Gütersloh (2011)

9. Wagner, M., Johann, D., Kritzinger, S.: Voting at 16: Turnout and the quality of vote choice. Electoral Studies 31(2), 372-383 (2011)

10. Parycek, P., Diendorfer, G., Maier-Rabler, U., Innen, M., Schossboeck, J., Wirth, M., Neumayer, C.: Internetkompetenz von SchülerInnen. Themeninteressen, Aktivitätsstufen und Rechercheverhalten in der 8. Schulstufe in Österreich. In: Donau-Universität Krems, Studienbericht (2010)

11. Barata, G., Gama, S., Jorge, J., Gonçalves, D.: Improving Participation and Learning with Gamification (2013), http://web.ist.utl.pt/gabriel.barata/wpcontent/papercite-data/pdf/barata2013c.pdf (accessed March 21, 2014)

12. Newton, K.: Trust, Social Capital, Civil Society, and Democracy. International Political Science Review 22(2), 201-214 (2001)

13. Spescha, P.: Vertrauen in die heimische Politik auf dem Tiefpunkt. In: Wirtschaftsblatt 10.12.2012 (2012),

http://wirtschaftsblatt.at/home/nachrichten/oesterreich/1299

$460 /$ Vertrauen-in-heimische-Politik-auf-dem-Tiefpunkt

(accessed March 21, 2014)

14. Statista 2014, Europäische Kommission. "Wie sehr vertrauen Sie der österreichischen Regierung?"

http://de.statista.com/statistik/daten/studie/284876/umfrage /umfrage-in-oesterreich-zum-vertrauen-in-die-regierung-2013/ (accessed March 21, 2014).

15. Statista 2014, Europäische Komission. "Welchen Politikern vertrauen Sie am meisten?" http://de.statista.com/statistik/daten/studie/191776/umfrage/ vertrauen-in-politiker/ (accessed March 21, 2014) 